\section{Lean: increase efficiency in stroke patient care}

Lean: increase efficiency in stroke patient

care

Maud Heijndermans

Laurens Rotterdam, Rotterdam, Netherlands

Alexander Maas

Rotterdam School of Management, Erasmus Universiteit Rotterdam, Rotterdam, Netherlands

Diederik Dippel

Department of Neurology, Erasmus Medical Center, Rotterdam, Netherlands, and Bianca Buijck

Rotterdam Stroke Service, Rotterdam, Netherlands and Erasmus MC University Medical Center, Rotterdam, Netherlands

\begin{abstract}
Purpose - Many healthcare organizations are looking for methods, such as Lean, to reduce their costs and increase the productivity of their professionals. The Lean method looks at every step in every process to assess if this step adds value for the customer or not. The aim of this study was to explore the value adding and nonvalue adding process steps in stroke patient admission in an integrated care stroke service in the Netherlands. Design/methodology/approach - This study focused on discharge of stroke patients from hospital acute treatment, and they were admitted for rehabilitation. According to the Grounded Theory, value stream mapping, organized interviews and expert meetings and coded was used. A configuration analysis was used to distinguish aggregates and configurations.

Findings - The most reported issues concerned in the paper are as follows: (1) insufficient internal logistics in the hospital, (2) miscommunication about medical readiness for discharge of the patient, (3) missing or delayed medical patient information, (4) overlapping discharge interviews, (5) unsafe transfer of sensitive information and (6) waiting lists and queuing up in rehabilitation facility.

Originality/value - At least six main areas of waste were identified in this stroke service, and they form the target for waste reducing activities. The results give insight in possible wastes in healthcare organizations and are therefore beneficial for other healthcare organizations which are planning to reduce wastes.
\end{abstract}

Keywords Stroke, Lean, Process, Integrated care, Efficiency

Paper type Case study

\section{Background}

Many healthcare organizations are considering methods to reduce their costs and increase the productivity of their employees. In a world where efficiency has a major role in business processes and where healthcare facilities are more and more managed like businesses, it might not be a surprise that healthcare facilities use frameworks that are formally designed and implemented for the profit segment. One of the methods frequently used in this segment is Lean. Lean has proven itself over the years in the production industry as a method that focuses on the client, reducing costs and increasing productivity all at the same time. Besides

(C) Maud Heijndermans, Alexander Maas, Diederik Dippel and Bianca Buijck. Published by Emerald Group Publishing Limited. This article is published under the Creative Commons Attribution (CC BY 4.0) licence. Anyone may reproduce, distribute, translate and create derivative works of this article (for both commercial \& non-commercial purposes), subject to full attribution to the original publication and authors. The full terms of this licence may be seen at http://creativecommons.org/licences/by/4.0/ legalcode

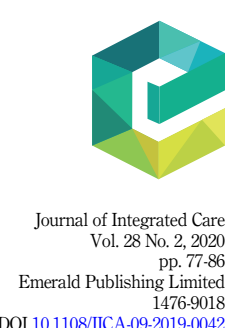

DOI 10.1108/JICA-09-2019-0042 
JICA

28,2

this, Lean found its place in the service industry and we see more and more Lean research within healthcare as well (D'Andreamatteo et al., 2015).

According to Black et al., (2016), a definition of Lean is a "Patient-centered approach to managing and delivering care that continuously improves how work is done. All parts of the production system are focused to eliminate waste while continuously increasing the percentage of value-added work." Lean can increase patient and staff satisfaction, cut waste, clutter and confusion and eliminate defects, lower costs and raise profitability. The Lean method looks at every step in every process to assess if this step adds value for the customer (patient) or not (Womack et al., 2007). If not, the step should be discarded. In terms of Lean, we speak about wastes. Reducing mistakes is an example of eliminating wastes. According to the Lean methodology, eight types of waste can be determined: (1) Defects: services and products that are not required or incorrect and need resources to adjust, 2) Overproduction: over-producing of a service or product which is not immediately required for use, 3) Waiting: waiting for equipment, information or instructions in order to complete the process, (4) Non-Utilized Talent: ineffectively engaging of employees or skills, (5) Transport: the unnecessary or lack of transport of information, people or items, (6) Inventory: information or inventory that is not used or not well stored, (7) Motion: unnecessary motion of information, people or equipment and (8) Overprocessing: using more advanced materials or services than necessary. These eight wastes are the origin of all the unbeneficial activity within organizations (Womack et al., 2007).

While Lean appears to be one of the frameworks that might improve healthcare at this moment, there is not enough evidence to state that implementation of Lean leads to better patient reviews (Poksinnska, 2010). Research by Holden (2011) shows that implementing Lean is usually focused on door-to-needle time or time spend in the healthcare facility. However, one of the researches also shows that implementing Lean also results in less stress for employees and a better ability to handle aggression from patients. In the literature, most reported wastes by patients seem to be waiting lists and increased length of stay in facilities, resulting in a decreased patient satisfaction. For example, in the study of Koné Péfoyo and Wodchis (2013) efficient planning at admission is important for patients to feel satisfied and therefore a smooth admission process is deemed necessary.

Moreover, most of the existing research on Lean within healthcare focuses on the first three principles of Lean: determine value for the patient, map the value streams and create flow to eliminate wastes. As most of the research concerning Lean within healthcare is relatively young, long-term effects of the Lean framework (such as producing on demand of the patient (pull-system) and striving for perfection), are not yet fully researched.

Healthcare however can be seen as multifaceted system with several units that are dependent from each other in their processes. If more organizations are involved, we often refer to it as an integrated care service. For example, delivering stroke care in integrated care services means that patients receive care in multiple steps in several healthcare facilities by numerous professionals, according to the clinical phase of stroke. During the past years, several definitions of integrated care were developed. According to Goodwin (2016), there are in general four definitions of integrated care: a health system-based definition, a manager's definition, a social science-based definition and a definition based on the perspective of the patient. Frequently, returning themes in the literature are: coordination across different levels, multidisciplinary collaboration, coherent and seamless care, care is patient centered and focused on patient satisfaction, efficacy, avoiding overlapping activities, optimum capacity planning and improved flow and cost reduction.

An integrated care service can be seen as a network of providers working together aiming to deliver coherent and patient-centered integrated care (Vat et al., 2016). In order to deliver continuity of care in an integrated care service, multidisciplinary professionals need to work together. They should have a continuous focus on development and improvement of healthcare and the integrated stroke service. This will result in increased patient satisfaction 
and cost-effective care. This is where the integrated care principles and the Lean methodology meet each other.

The Lean culture as well as healthcare require aspects such as teamwork, a high degree of collaboration and sufficient communication (Poksinska, 2010). And that is what particularly characterizes integrated care services (Zonneveld et al., 2018). Therefore, the Lean methodology should be suitable for implementation in healthcare, since the goals of Lean and integrated care services are not different: work in a coordinated way, in collaboration with others and have shared responsibility to improve patient outcomes and quality of care, work more efficiently and reduce costs of healthcare (Poksinska, 2010) (Zonneveld et al., 2018). The current study shows what healthcare facilities can learn from a methodology that was originally designed for the production industry. Therefore, the aim of this study was to get insight into the value adding and non-value adding process steps in stroke patient admission in an integrated care stroke service in the Netherlands. In the current study, we used a qualitative study design.

\section{Methods}

In the current study, we explored the patient journey of stroke patients, who are discharged from hospital acute treatment, and they are ready to start their clinical medical rehabilitation. Our research is executed in the Rotterdam Stroke Service, a collaboration of 19 healthcare organizations, which includes eight hospitals, one specialist rehabilitation center, nine geriatric rehabilitation centers (in skilled nursing facilities) and a community network. The current study involves one university hospital, a specialist rehabilitation center and a geriatric rehabilitation center.

\section{Data collection}

\section{Site/service}

We studied the transfer from hospital stroke unit to either specialist rehabilitation center or geriatric rehabilitation center. Current local guidelines in this stroke service state that the patient should preferably be transferred to either a rehabilitation center or a geriatric rehabilitation unit in a skilled nursing facility within five days, if the condition of the patient allows transfer. The day the patient is admitted to the stroke unit in the hospital counts as day one. This guideline is in place for every patient with a stroke, and it is used in all eight hospitals affiliated with the Rotterdam Stroke Service.

\section{Data collection process}

We used a quantitative approach to study the length of stay in the hospital and transfer time of stroke patients. This part of quantitative analysis was merely to define if the stroke service currently fitted the local guidelines. For this study, we used a qualitative, normative and explorative approach. We used a qualitative approach to generate theory using interpretative knowledge from multiple disciplines. We used the normative approach, according to the framework created by Eriksson and Koivalainen (2016), as we were investigating the intended action to improve the current process. Since we used an explorative research, a method to diagnose the current situation and give an advice for the future, we chose for naturalistic inquiry (Erlandson et al., 1993). We have used interview techniques with the professionals involved and studied which problems these professionals potentially experience in their daily work.

In order to collect all the important data, we used interviewing and value stream mapping (VSM). Furthermore, we used research journals to capture all the information gathered during the naturalistic inquiry process. In these research journals, conversations with employees, 
JICA

28,2

remarkable events and venue were described. The last item that was added to the data was the documents which were received from the experts (i.e. current protocols, application forms from the different healthcare facilities, overview of the availability in the facilities at that time).

\section{Ethics statement}

We have respected confidentiality and anonymity of the professionals, if they chose to remain anonymous. All professionals have read their interviews and have consented the use of information from the interviews. Data in the research journals were anonymized. We did not collect patient-data other than their anonymized length of stay in the organizations of the integrated care service. Therefore, full ethical approval of the research was not deemed necessary.

\section{Data analysis}

In order to analyze this data, several approaches were chosen. For coding the interviews, Glaser and Strauss' Grounded Theory methodology was used (1967). We used the first two steps of Grounded Theory (open coding and focused coding) to have a clear impression of the returning themes within the interviews.

The results of the coding were processed in a story, using the storytelling method. This method was chosen because it gave the opportunity to integrate all the different experts' opinions in one result, without losing any information. Furthermore, we used a configuration analysis to distinguish aggregates and configurations, in order to diagnose the different problems in this integrated care service (van Dongen et al., 1996). After the configuration analysis, we organized a VSM (most commonly applied Lean tool in healthcare), with all the experts to discuss the most common problems. In addition, possible solutions were generated as a team of healthcare experts rather than three different organizations. We used the typology of wastes of Womack et al. (2007) to label the wastes within the different topics. We evaluated all interviewees' opinions regarding possible causes of delay. We did this to identify possible ways to improve the process and, therefore, to avoid delays.

\section{Results}

From the interviews, we could identify six different topics that were discussed by all of the professionals in the stroke service. These six topics could be defined as: (1) insufficient internal logistics in the hospital, (2) miscommunication about medical readiness of the patient, (3) missing or delayed medical patient information, (4) overlapping discharge interviews, (5) unsafe transfer of sensitive information and 6) waiting lists and queuing up in rehabilitation facility. These six topics were according to the professionals, most responsible for delays in the process and, consecutively, responsible for longer hospitalization of the stroke patient and a patient that is not always fully informed about the upcoming transfer. Data of six consecutive months in the hospital in 2016 show that the mean of length of stay of stroke patients (both hemorrhage and ischemic) is 10 days and 92 percent of the patients exceed the four-day limit.

\section{Insufficient internal logistics in the hospital}

The neurologist may consult, for example, the cardiologist. The process of consultation usually takes a maximum of two days. In these two days, there is time spent waiting for the cardiologist. If the cardiologist decides that they need to run more tests, this process takes even longer. "Complex patients require more testing done by different professions. The results usually get back in a few days, but you might need to do additional unforeseen testing. If this is 
the case, the transfer date of the patient might change completely." When consultation leads to more tests, the patient cannot be transferred, although the rehabilitation facility has been planning personnel and a bed for this patient. This delay normally only occurs when extra tests are needed. Furthermore, another waste mentioned in the interviews was that changes in the medical condition of the patient are not communicated often enough or not through the right processes, which results in cancelation of transfers. The abovementioned wastes can be categorized as (3) Waiting, (5) Transport and (7) Motion.
Lean: increase efficiency in stroke patient

care

\section{Miscommunication about medical readiness of the patient for transfer to rehab}

With this topic, we refer to the fact that the patient has to be medically ready for transfer. This means that the patient has no other tests waiting or is no longer dependent on intravenous therapy, ventilator or cannulas. Especially the rehabilitation facilities remark this as a problem. In practice, the estimation on day two of the recovery process is often too early to have a clear prospective of the possible recovery of the patient. This leads to many cancellations and many resources of the rehabilitation facility being wasted on waiting and checking if the patient is indeed transferring to the rehabilitation facility on a particular day. "It occurs that the patient improves significantly and can be transferred to home directly from the hospital, but we have already started the admission process in the rehabilitation facility. In these situations we do not have time to open the process for another patient." The nurse ultimately discharges the patient, however, communication about discharge is not always communicated through the right processes, in time and complete. The abovementioned wastes can be categorized as (4) Non-utilized talent and (7) Motion.

\section{Missing or delayed medical patient information}

Third topic mentioned by the professionals is the fact that a lot of medical transfer papers are incomplete. "The information that is occasionally missing are the medical transfer papers. Mostly the transfer papers from the nurses are available." These transfer papers are important for the professionals in the rehabilitation facility as these contain all possible medical information of the patient, such as medication or specific genetic conditions to take into account when treating this patient. The lack of these medical transfer papers causes a risk for the treatment of this patient and can result in the family of the patient feeling uninformed. Most rehabilitation facilities refuse to transfer patients without these papers. Sometimes the papers are sent through e-mail or fax after the patient has been transferred to another healthcare facility. Furthermore, transfer is only possible during office hours and delay is also caused by the inability to transfer patients during the weekends. The abovementioned wastes can be categorized as (1) Defects, (3) Waiting and (5) Transport.

\section{Overlapping discharge interviews}

In the current process, there are two separate discharge interviews. Firstly, the neurologist informs the patient about the discharge, the transfer and all other relevant medical information. Secondly, the nurse informs the patient about any other medical information regarding the patient's stay in the hospital. Both discharge interviews are necessary in order to fully inform the patient about his or her condition and the next steps in the rehabilitation process. "We are working on organization of a combined discharge interview. In this case, if the patient has any questions, we can both answer those questions. This should provide more clarity for the patient." We chose to put this problem in the workflow of the neurologist, as they are in the lead. The abovementioned wastes can be categorized as (1) Defects, (4) Non-utilized talent, (5) Transport and (7) Motion. 
JICA

28,2

82

\section{Unsafe transfer of sensitive information}

The fifth topic concerns the safety of transfer of sensitive information between healthcare facilities. If the medical transfer papers are not ready when the patients' transfer takes place, the transfer papers are generally sent later. Additional to the risks it creates for the patient, as discussed in the second topic, it also creates the risk of losing sensitive information about the medical condition of the patient. Each healthcare facility has implemented its own electronic patient system, and the different systems are not interconnected with each other. About an integral system (secure e-mail and an online patient information system for all the cooperating organizations): "Such a system is designed to safely transfer medical information. We would be able to see it when the hospital has a question. We would no longer be dependent on the documents send by the transfer nurse." As this topic occurs in almost all of the workflows, this appears to be a significant problem for the communication and collaboration between the healthcare facilities. The abovementioned wastes can be categorized as (1) Defects and (6) Inventory.

\section{Waiting lists and queuing up in rehabilitation facility}

The last topic mentioned by multiple professionals within the stroke service, is the information about the waiting lists of the rehabilitation facility. There appears to be too little information about the current waiting times and the fluctuation of availability in the rehabilitation facility. The communication is currently not optimal, according to the interviewed professionals. Sometimes, the patient is already being transferred to the rehabilitation facility, while the neurologist who should refer the patient is not aware of this transfer, as the information about the availability of a rehabilitation bed came too late and too sudden. "I think it's fair to the patient to communicate how long the waiting time for the next healthcare facility will be. If the waiting time is too long in the opinion of the patient, we can start a secondary trajectory for another facility. If there is a waiting list now, we do not know what place the patient has on this waiting list. We do not have concrete information about when the can transfer the patient. More information would give the patient more clarity." The abovementioned wastes can be categorized as (2) Overproduction and (5) Transport.

\section{Discussion}

The aim of this study was to explore the process steps and their value in an integrated care stroke service in the Netherlands. According to our findings, waste takes up a relatively large part of the process in stroke healthcare facilities and the waste can be encountered across domains. We discuss the various domains in the following sections.

Insufficient internal logistics within the hospital seem to form one of the largest obstacles in the workflows of the professionals. A lot of time is wasted on waiting for communication from colleagues, waiting for test results and waiting for medical equipment to be ready for the patient, which may lead to unsatisfied patients. Blackmore and Kaplan (2016) state that Lean implementation can only be successful if it is executed from a perspective on the needs of the patient. Professionals seem to have less time to effectively spend with their patients if non-value adding tasks continue to exist in these workflows. In order to reduce wastes in the workflows of stroke services, the professionals need to look critically at the current flow, redesign the flow based on the patients' needs and reduce wastes as much as possible.

Changes in the medical condition of the patient often lead to problems in discharging the patient from the hospital to the following rehabilitation facility. Research shows that introducing Lean in the entire value chain could have a positive effect on all the individual organizations (Hartono et al., 2015), as one of the key principles of Lean is to create flow 
throughout the process. Creating flow throughout the entire value chain of stroke patients, could potentially benefit all the individual organizations. Introducing Lean in the entire value chain would also imply that the entire value chain has to work together in order to improve. This would mean better communication and probably less cancellations. Therefore, we encourage the facilities to work together to reduce the number of failed discharges when the medical condition of the patient changes.

In this study, there are three main topics that have the same underlying technology problem:

(1) Lack or incompleteness of medical transfer papers appears to be one of the biggest wastes of the current process. This is something we have not only found within the researched hospital but also there are more known cases within the Netherlands (Staalduinen, 2018).

(2) Professionals would like to encrypt the sensitive data and information before sending it to others, because they are worried that information is being transferred to the wrong person. Mazzocato et al. (2010) elaborate that the analysis of mistakes would result in a more awareness of these mistakes and could prevent these mistakes in the future. Regularly analyzing these flaws in the process, would create awareness and can reduce the chances of this mistake being made again. For example, professionals should double check the process instead of assuming that something has already been done. This could reduce failures that have great impact on the patients and are leading to reduced quality of care.

(3) The conventional methods, such as certified letters or faxing, take considerable time. Using a faster and Leaner way of transferring sensitive information, would eliminate the waste of waiting. One of the examples mentioned by the employees would be secure e-mail or an online patient information system for all the cooperating organizations. Removing unnecessary actions results in more time to spend on other necessary processes, thus creating value for the patient.

The use of an electronic information system might solve the three abovementioned problems. Unfortunately, the use of electronic information systems in healthcare delivery across clinical pathways is not yet common or fully executed in the Netherlands. Despite the efforts in implementing electronic information systems, there is still a lot to discover. Nevertheless, in the integrated care service in this study, several plans were executed in the past years.

Firstly, in the region of Rotterdam secure e-mail was implemented and has reached the highest adoption grade of secure e-mail in healthcare in the Netherlands. Secondly, sharing of information, such as images (X-ray) and documents on basis of a regional infrastructure, the standards of "integrating the healthcare enterprise" (IHE), is available for several organizations in the Rotterdam area. Unfortunately, they are not yet available for all organizations. Within the IHE standards, the industry and healthcare professionals seek to improve information-sharing in healthcare through computer systems (Adenuga et al., 2015). If these systems are developed in accordance with IHE standards, it is more effective and easier to share information. Thirdly, there is a national service point (Landelijk Schakelpunt, LSP), in which professionals can share medical information with each other in a safe infrastructure (https://www.vzvz.nl). At this moment this is only available for general practitioners and pharmacists. It is not a database, all patient information is stored in the patient files from the general practitioner and pharmacist. However, via Landelijk Schakel Punt (LSP), professionals are able to view information if the patient consented to share information. Also, by using opt-in, the owner of an e-mail address agrees explicit to receive email from a beforehand determined e-mail list.

These activities need further development although it will take years to fully establish them in the entire Rotterdam Stroke Service.
Lean: increase efficiency in stroke patient

care 
JICA

28,2

84

Before the patient can be discharged, he or she needs to receive all the discharge information from the nurse and the neurologist. Research by Wilhelm et al. (2014) indicates that using Lean in healthcare reduces unnecessary registrations and appointments which could lead to a significantly positive effect in effectivity. If these two discharge moments were to be combined into one, this would eliminate the waste of waiting for the patient and would result in a completely informed patient.

Transfer coordinators work on reducing waiting lists by implementing an up-to-date website, on which the doctor who refers the patient can check the current waiting list and the current availability. This approach uses the first principle of the Lean according to Womack et al. (2007). They claim that identifying the patient and specifying the value for this patient is the first principle of Lean. There are some examples of facilities that communicate proactively on a daily basis to inform other facilities and patients about availability. This ought to result in increased transparency and should reduce wastes in transport and waiting time.

\section{Limitations}

This research is conducted in a limited number of healthcare facilities in an integrated care service. The interviewing process was designed based on Rubin and Rubin (2012), who indicated that the interviews should be seen as a conversation that brings profounder insights into the current situation. Therefore, the interviewees were the experts, as they all fulfill a different role in the integrated care service for stroke patients. The strength of this research lies in the different methods used in order to conduct this study. Using naturalistic inquiry has resulted in a sincere and thorough story from employees involved in the process. Another strength of this study is the completeness of the process. All organizations in the supply chain have been studied and questioned. This gives an elaborated view of different paths a patient takes. To be able to generalize this research to a broader perspective, more research in the processes that influence length of stay within integrated care services is needed. Furthermore, Lean definitions are not well described in the literature, especially according to healthcare (Rotter et al., 2019) and also most of the research conducted in healthcare regarding Lean management has been done in a relatively short period of time. Consequently, the long-term effects are mostly not well investigated in these Lean studies. This can be considered as a weakness. Therefore, it is difficult to draw definite conclusions.

\section{Conclusion}

Overall, the professionals in this integrated care organization should continue to communicate efficiently with each other, in order to create a flow in the current processes. The suggestions made in this study help to increase the communication between and in organizations and may considerably reduce waiting time. With communication and dedication, the current wastes can be eliminated. However, it is important to keep the optimal situation for the patient in mind when redesigning the processes, as this increases the chances for sustaining the improvement.

Despite the relatively weak descriptions of Lean definitions in the literature (Rotter et al., 2019), we consider the Lean methodology very useful in healthcare. The topics (wastes) found in this research were closely related to the key aspects of healthcare: teamwork, a high degree of collaboration and sufficient communication. The drive for improvement is not different for healthcare professionals than for employees in the industry. It is important to have commitment, to seek for participation and experts should be recognized in their knowledge, experience and skills. Professionals whom are given responsibility will take the initiative to improve, but consequently they need support from all professionals at all levels in all the involved organizations to make great things happen. 


\section{References}

Adenuga, O.A., Kekwaletswe, R.M. and Coleman, A. (2015), "eHealth integration and interoperability issues: towards a solution through enterprise architecture", Health Information Science and Systems, Vol. 13 No. 3, p. 1, doi: 10.1186/s13755-015-0009-7.eCollection.

Black, J.R., Miller, D. and Sensel, J. (2016), The Toyota Way to Healthcare Excellence: Increase Efficiency and Improve Quality with Lean, HAP/Health Administration Press, Chicago, Illinois.

Blackmore, C.C. and Kaplan, G.S. (2016), "Lean and the perfect patient experience", BMJ Quality and Safety, Vol. 26 No. 2, pp. 85-86, doi: 10.1136/bmjqs-2016-005273.

D'Andreamatteo, A., Ianni, L., Lega, F. and Sargiacomo, M. (2015), "Lean in healthcare: a comprehensive review”, Health Policy, Vol. 119 No. 9, pp. 1197-1209, doi: 10.1016/j.healthpol.2015.02.002.

Eriksson, P. and Kovalainen, A. (2016), Qualitative Methods in Business Research, Sage, Los Angeles, CA.

Erlandson, D.A., Harris, E.L., Skipper, B.L. and Allen, S.D. (1993), Doing Naturalistic Inquiry: A Guide to Methods, Sage, London.

Glaser, B.G. and Strauss, A. (1967), The Discovery of Grounded Theory: Strategies for Qualitative Research, Aldine Publishing, New York, NY.

Goodwin, N. (2016), “Understanding integrated care”, International Journal of Integrated Care, Vol. 16 No. 4, pp. 1-4, doi: 10.5334/ijic.2530.

Holden, R.J. (2011), "Lean thinking in emergency departments: a critical review", Annals of Emergency Medicine, Vol. 57 No. 3, pp. 265-278.

Hartono, Y., Astanti, R.D. and Ai, T.J. (2015), "Enabler to successful implementation of lean supply chain in a book publisher", Procedia Manufacturing, Vol. 4, pp. 192-199, doi: 10.1016/j.promfg. 2015.11.031.

Kon!e P!efoyo, A.J. and Wodchis, W.P. (2013), "Organizational performance impacting patient satisfaction in Ontario hospitals: a multilevel analysis", BMC Res Notes, December, Vol. 5 No. 6 , p. 509, doi: 10.1186/1756-0500-6-509.

LSP. National Service Point, https://www.vzvz.nl/over-het-lsp/hoe-werkt-het-landelijk-schakelpunt (accessed 19 December 2019), (In Dutch).

Mazzocato, P., Savage, C., Brommels, Aronsson, H. and Thor, J. (2010), "Lean thinking in healthcare: a realist review of the literature”, BMJ Quality and Safety, Vol. 19 No. 5, pp. 376-382, doi: 10.1136/ qshc.2009.037986.

Poksinska, B. (2010), "The current state of lean implementation in health care", Quality Management in Health Care, Vol. 19 No. 4, pp. 319-329, doi: 10.1097/QMH.0b0113e3181fa07bb.

Rotter, T., Plishka, C., Lawal, A., Harrison, L., Sari, N., Goodridge, D., Flynn, R., Chan, J., Fiander, Poksinska, B., Willoughby, K. and Kinsman, L. (2019), "What is lean management in health care? Development of an operational definition for a cochrane systematic review", Evaluation and the Health Professions, Vol. 42 No. 3, pp. 366-390, doi: 10.1177/0163278718756992.

Rubin, H.J. and Rubin, I.S. (2012), Qualitative Interviewing: The Art of Hearing Data, 3rd ed., Sage, Thousand Oaks, CA.

Staalduinen, A.M. (2018), "De medische overdracht", Medisch Contact, Vol. 39 No. 8, pp. 1497-1499, (In Dutch).

Van Dongen, H., de Laat, W. and Maas, A.J.J.A. (1996), Een Kwestie Van Verschil: Conflicthantering En Onderhandeling in Een Configuratieve Integratietheorie, Eburon, Delft, (In Dutch).

Vat, L., Middelkoop, I., Buijck, B. and Minkman, M.M.N. (2016), "The development of integrated stroke care in The Netherlands: a benchmark study", International Journal of Integrated Care, Vol. 16 No. 4, 12, pp. 1-10, doi: 10.5334/ijic.2444.

Wilhelm, B., Sinjewel, A., den Brok, M., van Beneden, M. and Kool, R. (2014), "Hoe kleine procesverbeteringen grote winst op kunnen leveren", in Rouppe van der Voort, M. and Benders,

Lean: increase efficiency in stroke patient

care 
J.G. (Eds), Verder met Lean in de zorg: naar de kern van de zaak, Boom Lemma, Amsterdam, (In Dutch).

Womack, J.P., Roos, D. and Jones, D.T. (2007), The Machine that Changed the World, Simon and Schuster, London.

Zonneveld, N., Driessen, N., Stüssgen, R.A.J. and Minkman, M.M.N. (2018), "Values of integrated care: a systematic review", International Journal of Integrated Care, Vol. 18 No. 4, pp. 1-12, doi: $10.5534 /$ ijic.4172.

\section{Corresponding author}

Maud Heijndermans can be contacted at: maudheijndermans@gmail.com

For instructions on how to order reprints of this article, please visit our website: www.emeraldgrouppublishing.com/licensing/reprints.htm Or contact us for further details: permissions@emeraldinsight.com 